\title{
Comparison of the Amplicor Chlamydia trachomatis test and cell culture for the detection of urogenital chlamydial infections
}

\author{
M A Catry, M J Borrego, J Cardoso, J Azevedo, I Santo
}

\begin{abstract}
Objective-To compare the polymerase chain reaction (PCR) Amplicor Chlamydia trachomatis test with the cell culture method, in diagnosing urogenital chlamydial infections.

Subjects-439 patients (327 women and 112 men) attending one STD clinic and Family Planning and Gynaecological Clinics in Lisbon, Portugal, between November 1993 and March 1994.

Methods-In women, two endocervical swab samples were collected: one for PCR Amplicor and one for standard culture technique. Men were asked to submit $20 \mathrm{ml}$ of urine (first pass urine) for PCR Amplicor and one urethral specimen was taken for culture. The order of collection of the specimens was rotated every 50 patients. Discrepant results were further analysed by a second PCR with primers directed against the $C$ trachomatis major outer membrane protein (MOMP) and by direct fluorescent antibody (DFA).

Results-After analysis of discrepancies, the adjusted sensitivity and specificity of PCR on endocervical specimens were $92.9 \%$ and $100 \%$ and the positive and negative predictive values were $100 \%$ and 99.7\% respectively; on the urine samples these values were $100 \%, 99.1 \%, 100 \%$ and $99 \cdot 1 \%$, respectively.

Conclusion-These results indicate that the PCR Amplicor test is a rapid sensitive and specific assay for the detection of $C$ trachomatis in urogenital infections and provides a non-invasive technique for screening chlamydia infection in men.
\end{abstract}

(Genitourin Med 1995;71:247-250)

Keywords: Chlamydia trachomatis; PCR; Amplicor

\section{Introduction}

Chlamydia trachomatis infection is one of the most prevalent sexually transmitted diseases in the world. This prevalence is generally higher in STD clinics attenders, but $5 \%$ to $20 \%$ of women attending family planning clinics may be infected. Carriage of $C \mathrm{tra}$ chomatis may be asymptomatic in both women and men, providing a reservoir for infection. ${ }^{1}$

Recovery of $C$ trachomatis in cell culture has been considered the most sensitive and spe- cific standard method for diagnosis but it is quite laborious and requires cell culture facilities unavailable in many laboratories.

The polymerase chain reaction (PCR) technology developed in recent years allows the detection of small quantities of specific nucleic acids, using repeated amplification steps of a respective target sequence. PCR protocols for the detection of $C$ trachomatis have been proposed by different authors. ${ }^{2-8}$

We describe here the evaluation of a new PCR test developed by Roche Molecular Systems (RMS, N.J.) for detection of $C$ trachomatis (Amplicor $C$ trachomatis test), against a standard cell culture technique, in cervical and urine samples from 439 patients ( 327 women, 112 men) attending a clinic for sexually transmitted diseases and family planning clinics.

Discrepant results were analysed by a second PCR with primers directed against the $C$ trachomatis major outer membrane protein (MOMP).

Materials and methods

Patients These were 134 women and 112 men attending one STD clinic in Lisbon (high risk population) and 193 women attending family planning and gynecological clinics for reasons other than sexually transmitted diseases (low risk population).

Specimens From women, two endocervical swab samples were collected: one for Amplicor and one for standard culture technique. The order of collection was rotated every 50 patients.

Men were asked to submit $20 \mathrm{ml}$ of urine for PCR Amplicor and one urethral specimen was taken for culture. The urine specimens were always collected prior to the urethral specimens.

All cervical specimens to be analysed by PCR were placed in $1 \mathrm{ml}$ of transport medium supplied by the manufacturer and stored at $4^{\circ} \mathrm{C}$ prior to processing and amplification (within seven days). The urines were stored at $4^{\circ} \mathrm{C}$ and processed within four days.

The specimens for culture were placed into 2 sucrose phosphate chlamydial transport media and stored at $4^{\circ} \mathrm{C}$, or when not tested within 48 hours after collection, at $-70^{\circ} \mathrm{C}$.

Chlamydia Culture McCoy cells were cultured on $12 \mathrm{~mm}$ diameter coverslips in Eagle's medium supplemented with $10 \%$ calf serum. After growth to monolayers, cell 
cultures were treated with cycloheximide (1 $\mathrm{mg} / \mathrm{l})$.

Cultures were inoculated with $0.2 \mathrm{ml}$ of each specimen in transport medium, centrifuged for one hour at $3000 \mathrm{~g}$ and incubated at $36^{\circ} \mathrm{C}$ in $5 \% \mathrm{CO}_{2}$ for 48 hours. Following fixation with methanol, monolayers were stained with fluorescein conjugated monoclonal antibody (Syva Company, Palo Alto). Chlamydial inclusions were assessed with a Zeiss fluorescence microscope. C trachomatis strains obtained from positive specimens were subcultured and conserved at $-70^{\circ} \mathrm{C}$.

Amplicor $C$ trachomatis test PCR amplification and detection of PCR amplified DNA were carried out according to the manufacturer's instructions. The Amplicor kits were kindly provided by Roche Diagnostic Systems, Portugal. The test was run in three separate areas: area 1 dedicated to the preparation of reagents for amplification, area 2 for specimen preparation and area 3 used for amplification and detection of amplified DNA.

Cervical specimens: the swabs specimens were placed in a sodium dodecyl sulphatebased transport tube and were processed within seven days of collection. One millilitre of specimen diluent (Amplicor, RMS) was added to the transport tube. After vortex mixing, diluted specimens were allowed to stand 15 minutes at room temperature. Then, using a micropipette with plugged tips, $50 \mathrm{ml}$ was removed and mixed with $50 \mathrm{ml}$ of Master Mix with AmpErase (Amplicor, RMS) containing AmpliTaq, biotinylated primers, dATP, dCTP, dGTP, dUTP and uracil-n-glycosylase (to prevent amplicon contamination). The remainder of the specimen was conserved at $-20^{\circ} \mathrm{C}$.

Male urines were stored at $+4^{\circ} \mathrm{C}$ and tested within four days of collection. After storage, the urines were checked for the presence of a precipitate. If a precipitate was present, specimens were warmed at $37^{\circ} \mathrm{C}$ with mixing to dissolve the precipitate.

Ten millilitres of urine was transferred to a conical polypropylene tube, and centrifugated at $1500 \mathrm{~g}$ for 10 minutes at room temperature. The cell pellet was added to $2 \mathrm{ml}$ of urine resuspension buffer and allowed to stand at room temperature for one hour. Two millilitres of urine diluent (Amplicor, RMS) was added to each tube, vortexed for $1 \mathrm{~min}$ and remained at ambient temperature for 10 minutes prior to PCR amplification.

Samples were subjected to 30 cycles of denaturation at $95^{\circ} \mathrm{C}$ and hybridisation and annealing at $60^{\circ} \mathrm{C}$ in a TC9600 thermal cycler (Perkin Elmer, Roche). The first cycle was held at $95^{\circ} \mathrm{C}$ for $5 \mathrm{~min}$ and at $60^{\circ} \mathrm{C}$ for $1 \mathrm{~min}$. The following cycles were held at $95^{\circ} \mathrm{C}$ for 30 $\mathrm{s}$ and at $60^{\circ} \mathrm{C}$ for $60 \mathrm{~s}$. After amplification, the samples were held at $72^{\circ} \mathrm{C}$ until addition of denaturation solution (Amplicor, RMS). Three amplification negative controls and one amplification positive control were included in each experiment. Denaturated amplicons were detected by oligonucleotide capture hybridisation (one hour at $37^{\circ} \mathrm{C}$ ) in a microtitre system with colorimeter detection using an avidin horseradish peroxidase system. The optical density (OD) was read in automated microwell plate reader at $450 \mathrm{~nm}$.

Optical density values greater than 0.50 were considered positive and those less than 0.25 , negative; those between 0.25 and 0.50 were retested. Negative controls were required to have $O D$ values less than 0.25 and the positive control with an OD greater than 2 for a test to be considered valid.

Discrepant results If a specimen produced a PCR Amplicor result discrepant with the cell culture, the test was repeated. If a disagreement was repeatedly observed, specimens were reamplified by using PCR primers directed against the $C$ trachomatis MOMP gene. The MOMP PCR assay utilised primers described by Sayada, et al. ${ }^{9}$ : CTU (5'ATGAAAAAACTCTTGAAATCGG-3') and CTL (5'-CAAGATTTTCTAGA(T/C) TTCAT(C/T)TTGTT-3').

Amplification was performed in a TC 9600 thermal cycler (Perkin Elmer), starting with one cycle of 7 minutes at $94^{\circ} \mathrm{C}$ and 5 minutes at $48^{\circ} \mathrm{C}$, followed by 35 cycles of: denaturation, $1 \mathrm{~min}$ at $94^{\circ} \mathrm{C}$; primer annealing, $1 \mathrm{~min}$ at $48^{\circ} \mathrm{C}$ and primer extension, $2 \mathrm{~min}$ at $72^{\circ} \mathrm{C}$, ending with the last cycle at the temperature of $72^{\circ} \mathrm{C}$ for 7 minutes.

PCR products were analysed by electrophoresis of $10 \mathrm{ml}$ of the amplification mixture on a $1 \%$ agarose gel stained with ethidium bromide. DNA was then detected by ultraviolet light exposure. RFLP using enzyme digestion by EcoRI was used to confirm the specificity of the PCR products.

\section{Results}

Women attending STD clinic

By the use of the cell culture, the prevalence of $C$ trachomatis in the high risk group of 134 women, was found to be $8 \cdot 2 \% \quad(11 / 134)$. From the 11 cell culture positive, $10(90 \%)$ were PCR Amplicor positive (table 1).

Two discrepant results were observed: one was positive by culture and negative by Amplicor and one was culture-negative and Amplicor-positive. The specimen which was positive by culture and negative by Amplicor,

Table 1 Comparison of the Amplicor test and cell culture results for $C$. trachomatis in samples from males and females

\begin{tabular}{|c|c|c|}
\hline & \multicolumn{2}{|c|}{ No. of samples using Amplicor test } \\
\hline & Positive & Negative \\
\hline \multicolumn{3}{|l|}{$\operatorname{Men}(n=12)$} \\
\hline Culture positive & 7 & 0 \\
\hline \multirow{2}{*}{\multicolumn{3}{|c|}{$\begin{array}{l}\text { Women attending } \\
\text { STD clinic } \\
(\mathbf{n}=134)\end{array}$}} \\
\hline & & \\
\hline Culture positive & 10 & 1 \\
\hline Culture negative & 1 & 122 \\
\hline \multirow{2}{*}{\multicolumn{3}{|c|}{$\begin{array}{l}\text { Women attending } \\
\text { Family Planning clinics } \\
(\mathrm{n}=193)\end{array}$}} \\
\hline & & \\
\hline Culture positive & 2 & 0 \\
\hline Culture negative & 0 & 191 \\
\hline
\end{tabular}


Table 2 Analysis of discrepant results

\begin{tabular}{llllll}
\hline $\begin{array}{l}\text { No. of patients with } \\
\text { indicated test pattern }\end{array}$ & Sex & Cell culture & $\begin{array}{l}\text { Amplicor } \\
\text { test }\end{array}$ & $\begin{array}{l}\text { PCR } \\
\text { (MOMP) }\end{array}$ & DFA \\
\hline 1 & F & + & - & + & ND \\
1 & F & - & + & + & + \\
1 & M & - & + & - & - \\
\hline
\end{tabular}

ND: not done.
(Syva, Microtrak) for the detection of elementary bodies (EB). No EBs were observed. The Amplicor result was considered a false positive result.

Therefore the overall sensitivity of the PCR of the PCR assay was $100 \%$ and its specificity $99.1 \%$; the positive and negative predictive values were respectively $100 \%$ and $99 \cdot 1 \%$.

when tested by the MOMP PCR in 2SP transport medium, had a positive result which indicated a culture true positive result. The specimen which was culture-negative, Amplicor positive, was further analysed by the MOMP PCR and the result was positive, which indicated a culture false negative result. A DFA test (Syva, Microtrak) was performed on the culture transport medium and the result was positive (table 2 ).

Therefore the overall prevalence (culture positive or both PCR test positive) in this group of patients was $9 \%(12 / 134)$.

The sensitivity, specificity, predictive value of positive result (PPV) and predictive value of a negative result (NPV) of the PCR Amplicor test were found to be $91 \%, 99 \cdot 2 \%$, $91 \%$ and $99.2 \%$ respectively, when compared with the cell culture assay. After analysis of discrepant results, the adjusted sensitivity, specificity, PPV and NPV increased to $91.7 \%$, $100 \%, 100 \%$ and $99 \cdot 2 \%$ respectively.

\section{Women attending Family Planning and Gynaecological Clinics}

Of the 193 paired samples obtained in this group, two were culture positive and Amplicor positive and 191 were negative by both methods (table 1). The overall prevalence was $1.03 \%$ and the sensitivity, specificity, positive and negative predictive values of the Amplicor test were $100 \%$.

Regarding the 327 women from the two groups, the revised sensitivity, specificity, PPV and NPV of the Amplicor assay were $92.9 \%, 100 \% .100 \%$ and $99.7 \%$ respectively.

The sensitivity and the specificity of cell culture compared with true positive samples were $92 \cdot 2 \%$ and $100 \%$.

\section{Men}

A total of 112 men attending one STD clinic in Lisbon were evaluated for $C$ trachomatis infection by the PCR Amplicor assay for urine specimens and the results were compared with those obtained by urethral cell culture. All patients complained of urethral symptoms. The prevalence of $C$ trachomatis by urethral culture was found to be $6 \cdot 3 \%(7 / 112)$.

Seven specimens were Amplicor positive and culture-positive and 104 specimens were negative by both tests (table 1). There was one discrepant result which was positive by Amplicor and negative by culture. This urine specimen, when analysed by the alternative MOMP PCR was negative. In addition, a DFA test of the urine was performed (table 2).

After centrifugation of $200 \mathrm{ml}$ of urine, $5 \mathrm{ml}$ of the resultant pellet was placed on a slide and fixed with methanol and stained with $C$ trachomatis monoclonal antibodies

\section{Discussion}

Cell culture has been considered the reference standard for detection of $C$ trachomatis on urogenital samples.

PCR protocols for the detection of $C$ trachomatis DNA in clinical specimens have been proposed by several authors because the sensitivity of the PCR technique is estimated to be higher than that of cell culture.

The Roche Amplicor $C$ trachomatis test is a standardised commercial assay that uses a rapid DNA amplification of the common $C$ trachomatis cryptic plasmid and a colourimetric microwell DNA hybridisation. It is a relatively easy method to process a high volume of specimens in approximately four hours.

In our study, the majority of cases gave clear results: all the 20 Amplicor positive specimens (13 cervical swabs and seven urines) yielded OD values more than 0.5 , and out of the 419 Amplicor negative specimens, 410 presented OD values less than $0 \cdot 25$. Only nine specimens (seven cervical swabs and two urines) had a borderline OD value (between 0.2 and 0.5 ) and when retested they were all negative.

In 327 cervical specimens our results show a sensitivity of $92.9 \%$ and a specificity of $100 \%$. Other studies reporting the evaluation of the Amplicor $C$ trachomatis test, refer to higher sensitivity values but similar specificity. ${ }^{10-12}$

In processing 327 cervical specimens, there were no false-positive results. The Amplicor test failed to detect one culture-positive specimen and detected one true-positive specimen that was culture-negative. case, the fact that the MOMP PCR test was positive on culture transport medium excludes the possibility that the culture was false-positive. Some authors had suggested that the presence of too much DNA matrix can inhibit amplification. ${ }^{11}$ We have tested, after dilution, this specimen (that showed 15 or more inclusions per field) and the Amplicor result remained negative. So the probable explanation is that the false negative Amplicor specimen resulted from swab to swab variability. In this study of two populations of women the sensitivity and specificity of the Amplicor These values were similar to the sensitivity and specificity values of the cell culture.

In male urine specimens, the Amplicor test was in our hands highly sensitive $(100 \%)$ and specific $(99 \cdot 1 \%)$, compared with urethral culture. In processing 112 urine specimens from symptomatic males, there was only one falsepositive Amplicor result. This specimen was negative by culture and by MOMP PCR and
In the Amplicor negative, culture-positive test were $92.9 \%$ and $100 \%$ respectively. 
no EBs were observed by DFA test of urine sediment; it was considered a true negative specimen.

The sensitivity and specificity values of the Amplicor test we have obtained in symptomatic males are higher than those reported in a study that has been published in the USA. ${ }^{12}$

These results show that the Amplicor assay for detection of $C$ trachomatis in male urine specimens is highly sensitive and specific, providing a very useful non-invasive technique. In conclusion, because of high sensitivity and specificity, the PCR Roche assay for $C$ trachomatis may be a good alternative to cell culture and especially useful for diagnosis of chlamydia in low prevalence populations.

1 Mardh PA, Paavonen J, Puolakkainen M. Chlamydia Publish Corp, 1989, New York.

2 Naer H, Drzoneck H, Wolf J, Doeberitz M, Petzold D. Detection of Chlamydia trachomatis in urogenital specimens by poly

3 Dutilh B, Bébéar C, Rodriguez P, Vekris A, Bonnet J, Garret $M$. Specific amplification of a DNA sequence common to all Chlamydia trachomatis serovars using polymerase chain reaction. Res Microbiol 1989;140:7-16.
4 Griffais R, Thibon M. Detection of Chlamydia trachomatis by the polymerase chain reaction. Res Microbiol 1989; 140:139-41

5 Ossewaarde JM, Rieffe $M$, Rosenberg-Arska $M$, Ossenkoppele PM, Nawrocki RP, van Loon AM. Development and clinical evaluation of a polymerase chain reaction test for detection of Chlamydia trachomatis. chain reaction test for detection of

6 Vogels WHM, van Voorst Vader, Schroder FP. Chlamydia trachomatis infection in a high risk population: comparison of polymerase chain reaction and cell culture for diagnosis and follow-up. $\mathrm{F}$ Clin Microbiol 1993;31:1103-7.

7 Ratti G, Moroni A, Cevenini R. Detection of Chlamydia trachomatis DNA in patients with non-gonococal urethritis using the polymerase chain reaction. $f$ Clin Pathol 1991;199:564-8

8 Wu C-H, Lee M-F, Yin S-C, Yang D-M, Cheng SF Comparison of polymerase chain reaction, monoclonal antibody based enzyme immunoassay, and cell culture for detection of Chlamydia trachomatis in genital specimens. Sex Transm Dis 1992;19:193-7.

9 Sayada C, Denamur E, Orfila J, Catalan F, Elion J. Rapid genotyping of the Chlamydia trachomatis major outer genotyping of the Chlamydia trachomatis major outer membrane protein by the polyme

10 Loeffelholz MJ, Lewinski CA, Silver SR, Purohit AP, Herman SA, Buonagurio DA, Dragon EA. Detection of Chlamydia trachomatis in endocervical specimens by polymerase chain reaction. $f$ Clin Microbiol 1992;30: 2847-51.

11 de Barbeyrac B, Pellet I, Dutilh B, et al. Evaluation of the Amplicor Chlamydia trachomatis test versus culture in genital samples in various prevalence population. Genitourin Med 1994;70:162-6.

12 Jaschek G, Gaydos CA, Welsh LE, Quinn TC. Direct detection of Chlamydia trachomatis in urine specimen from symptomatic and asymptomatic men by using a rapid polymerase chain reaction assay. $f$ Clin Microbiol rapid polymerase 